\title{
REGIÕES PURAS E IMPURAS: UMA BREVE REFLEXÃO SOBRES AS NATURALIZAÇÕES DA REGIÃO NA GEOGRAFIA
}

\author{
TADEU ALENCAR ARRAIS*
}

Universidade Estadual de Goiás

Os fatos são impuros.

Edgar Morin,

(Ciência com consciência)

Não seria exagero dizer que a região tem sido, ao longo da existência acadêmica da geografia, a categoria que mais despertou debates, seja do ponto de vista conceitual ou mesmo pragmático, com implicações nos procedimentos de regionalização e planejamento. O predomínio regional, pelo menos a partir do final do século XIX, acompanhou a evolução da geografia, especialmente na Europa com a influência de Vidal de La Blache renovando-se nos dias atuais com os debates em países como Estados Unidos e Inglaterra sobre os arranjos territoriais denominados "cidades-regiões" ou "cidades regiões globais" (AGNEW, 2000; Scott et all, 2001), assim como a emergência dos regionalismos em várias escalas, que vão da afirmação dos blocos econômicos à reivindicação de autonomia territorial (regional) em várias partes do planeta. Observando as relações entre o aparato conceitual de região e as sucessivas

\footnotetext{
* Doutorando do Programa de Pós-Graduação em Geografia da UFF. Professor da Universidade Estadual de Goiás, Campus de Anápolis.
} 
formações regionais ao longo dos séculos XX e início do XXI podemos dizer que, em certa medida, as naturalizações da região seguiram uma continuidade evidenciada pelos modelos regionais transportados ou mesmo adaptados para construções regionais diferenciadas, especialmente nos países subdesenvolvidos. Há, esse é o ponto de vista que adotamos aqui, uma naturalização da região: ora o critério natural, ora o critério econômico, em outros momentos o critério da divisão administrativa, enfim, uma idéia sempre presente que as regiões não seriam um produto da mediação entre as dimensões materiais e simbólicas da vida humana expressa e reconhecida numa dada base territorial. A tradição, ou melhor, a leitura da "tradição", impôs uma forma de pensar a região como uma construção pura e naturalizada, forjada como resposta para uma necessidade prática resultante da relação com a administração pública ou privada (regionalização) ou mesmo com a academia a partir da produção de teses, dissertações, ensaios etc. Nosso propósito é interrogar sobre a pureza das regiões, o que significa considerar suas naturalizações e desconfiar tanto do recorte quanto de quem recorta.

\section{A região: o "obstáculo" naturalizado}

A crítica elaborada por Lacoste (1994) ao "poderoso conceito-obstáculo", entendida por alguns como condenação à categoria região, não esgota uma das mensagens mais presentes na obra do autor. Lacoste tem um alvo e contra ele investe sua fina ironia: Vidal de La Blache. Seu objetivo é indagar sobre as influências da geografia vidalina na corporação de geógrafos, tendo como consequiência a despolitização do debate geográfico. Como na guerra, o ataque se estende para diversos fronts, sendo um deles a região "personagem vidalina". O título do capítulo, "A colocação de um poderoso conceito-obstáculo: a região personagem" já traduz um pouco das inquietações de Lacoste.

Fruto do pensamento vidalino, a 'região geográfica', considerada a representação espacial, senão única, ao menos fundamental, entidade resultante, pode-se dizer, da síntese harmoniosa e das heranças históricas, se tornou um poderoso conceito obstáculo que impediu a consideração de outras representações espaciais e o exame de suas relações. (LACOSTE, 1994: p. 64).

Lacoste (1994) coloca reticências, desconfia, dos procedimentos adotados por Vidal de La Blache para descriminar e adjetivar as regiões francesas como se elas sempre tivessem existido daquela forma e como se a ele fosse delegado o poder de identificar a "individualidade" e a "personalidade" dessas regiões. A crítica à corporação de geógrafos franceses resulta do culto que estes fizeram a Vidal de La Blache, não reconhecendo uma diferenciação no conceito de região em suas obras, especialmente no que toca ao livro A França do Leste, um legítimo livro de geopolítica, segundo Lacoste (1994). 
A força dessa representação "personagem" da região tem origem na naturalização desse conceito que impediu a consideração da "espacialidade diferencial" (LACOSTE, 1994). Era como se a região fosse a única e isolada escala de análise, contendo, nos seus limites (mesmo sendo o limite uma idéia humana) toda a sua história, capaz de auto-explicar-se. Para compreender a região era preciso apenas o talento da fina descrição da relação entre homens e a comunidade, já que, para o próprio La Blache, pelo menos no livro Princípios da Geografia Humana (1957:27): "A idéia de região é inseparável da idéia dos seus habitantes”. Disso resulta a primeira e mais eficaz naturalização, não reconhecida pela tradição geográfica herdeira de Vidal de La Blache. Essa tradição não foi capaz de reconhecer os múltiplos recortes regionais e perspectivas teóricas elaborados pelo mestre Vidal de La Blache. Mesmo nos dias de hoje nada nos autoriza a aprisionar a geografia vidalina numa única perspectiva de análise, ou seja, naturalizar e cristalizar seu discurso. ${ }^{1}$ Para Gomes:

Vidal não se restringiu a descrever realidades, ele também criou categorias, noções gerais interligadas que constituem a própria base de seu discurso teórico. A análise destas categorias e de seu papel pode, pois, revelar certos aspectos negligenciados da espistemologia vidalina.

(GOMES, 1996:198)

A divisão regional do Brasil de 1945 que resultou da adoção de um modelo teórico e depois de sua aplicação exemplifica o que chamamos de naturalização. Muito embora Fabio Guimarães (1942) tenha feito a opção pelas regiões naturais, por privilegiar a estabilidade e facilitar, desse modo, as séries estatísticas para a administração pública, sabia que esse não era o único modo de entender as regiões. Ocorre que esse modo "escolhido", arbitrado, foi vulgarizado e impresso desde então, sem grandes diferenças, nos livros didáticos, na grande mídia, nos planos regionais etc. No entanto o Nordeste de 1945 vai diferir do Nordeste de 1968 não apenas na forma (uma vez que inclui Sergipe e Bahia, antiga região Leste) mas também no conteúdo (agora, devido às mudanças, mais próximo "de um bloco histórico", PERIDES, 1994) que também será naturalizado. Uma naturalização ambiental imposta pelos desígnios da natureza. Uma naturalização histórica marcada pelas infelicidades do processo de colonização. Enfim, há motivos para acreditar que Deus tenha sido ingrato com o Nordeste! $!^{2}$

\footnotetext{
'Ozouf-Maringnier, M. \& ROBIC, M., (1995) chamam a atenção, a partir da consideração das obras de Vidal de La Blache, para as variações no pensamento vidalino, que vão, segundo os autores, do "naturalismo ao economicismo".

Sobre o Nordeste brasileiro, numa perspectiva bastante interessante, encontramos o trabalho de Albuquerque Jr., A Invenção do Nordeste e Outras Artes. Segundo esse autor, no capítulo denominado "Geografia em Ruínas": "O nordeste é filho da ruína da antiga geografia do país, segmentada entre Norte' e 'Sul". Como o próprio autor pondera, sua pretensão é "desnaturalizar a regiảo, problematizar sua invenção, de buscar a sua historicidade, no . campo das práticas e discursos" (Idem:26). O livro é polêmico e tem despertado debates sobre a existência discursiva $\mathrm{X}$ existência territorial da região.
} 
Em se tratando do Norte do Brasil a naturalização do ambiental ainda é pior. Esconde, sob a homogeneidade que permanece verde desde 1945, o processo de exploração que vem ocorrendo há décadas, não só em relação à expropriação de terra em função de atividade agromineral, mas toda ordem de conflitos fundiários e disputas envolvendo a indústria farmacêutica, com prática da biopirataria. O fato é que a grande maioria da população ainda é incapaz de pensar a Amazônia, tomada como região Norte, no plural. ${ }^{3}$ A naturalização foi incorporada ao imaginário popular. O princípio da homogeneidade foi cicatrizado, seguindo os limites municipais e estaduais. Esse é um outro obstáculo: a naturalização administrativa, ou pior, para utilizar o adjetivo político, a naturalização do político no velho mapa temático. A concatenação regional é perfeita, ainda mais quando incluído, desde 1945, os níveis de hierarquização com cinco grandes regiões, trinta regiões, setenta e nove subregiões e duzentas e vinte e oito zonas fisiográficas (RIBEIRO, 1993). Um conjunto de municípios forma as microrregiões, um conjunto de microrregiões forma as mesorregiões, esse conjunto de messorregiões forma as grandes regiões que formam, juntas, a nação brasileira. O quebra-cabeça completa-se: tem uma forma e uma escala, ambas subordinadas ao Estado Nação, ambas naturalizadas ${ }^{4}$.

Dessa maneira podemos dizer que a região esteve presa a uma forma e uma escala, talvez pelo fato de a idéia de região envolver diretamente a noção domínio, limite. Essa forma, como domínio homogêneo-fixo de uma paisagem natural ou cultural, objeto da descrição, ou como domínio funcional-fluxo marcado pelo reconhecimento de padrões funcionais (economia e cidade), esteve subordinada ao talento descritivo ou mesmo à técnicas de manipulação de dados e reconhecimento de diferenças no desenvolvimento territorial. A escala, por outro lado, esteve presa, talvez já o tenha nascido, ao Estado-Nação. Não por acaso o debate regional do século XIX teve relação direta com a formação do Estado territorial e a centralização do poder, em contraposição às autonomias regionais e locais. As regiões no interior do Estado-Nação, daí a emergência da questão regional e territorial como desafio ao desenvolvimento regional ser também uma forma de a região aparecer como sinônimo de regionalismo. Talvez por isso o discurso sobre o fim do regional coincida com o discurso neoliberal do fim do Estado Nação e fim também da região, uma vez que, com o desaparecimento da escala de existência, o regional

\footnotetext{
${ }_{3}^{3}$ Em pesquisa enfocando a construção de conhecimentos e o ensino da geografia, a partir da consideração de diversos conceitos elementares de geografia na $5^{*}$ e $6^{*}$ série, dentre eles a região, Cavalcante: (1998:52-53) escreve: "Quero dizer que a idéia de região assimilada pelos alunos parece ser uma idéia cristalizada, estática, naturalizadora, no sentido de que não está internalizada em seu conceito (ou pelo menos nas noçōes manifestas até aqui) a idéia de processo, de regionalização (que inclui a idéia de critérios), de dinâmica espacial que define regiōes".

A critica, nesse ponto, não vai para os modelos de regionalização necessários para a administração pública. No entanto, ao não discutir essas regionalizações em outros domínios, como no ensino, estamos desprezando as mudanças na formação territorial brasileira, incluindo, também, o debate sobre as áreas de fronteira econômica (Mercosul) e as economias regionais.
} 
também desapareceria. Nada como o pensamento mecânico para eliminar o debate sobre o regional.

Mas não nos deixemos enganar. É o fim da região pura, construída por "fatos puros" (MORIN, 1999), do obstáculo naturalizado por adjetivos perenes. Portanto, não devemos deixar de relacionar o discurso do fim da região à nossa dificuldade de renovação conceitual. Dizer que a região será sempre o que foi é não ter clareza dos limites e possibilidades do próprio conceito. Que outro conceito na geografia gozaria de tanto prestigio?

\section{Rompendo as naturalizações: um outro caminho é possível?}

A dificuldade de discutir regiões que não sejam puras, naturalizadas, vem do fato de termos que determinar o domínio da discussão regional (ciência, senso comum, administração pública etc) e ao mesmo tempo, já que a escolha tem relação com a ciência, determinar qual ciência e dentro dela observar as variações conceituais. $\mathrm{Na}$ geografia clássica, na geografia critica, nas perspectivas humanistas, na new geography, em cada uma dessas vertentes, dentre outras, a região assumiu caráter diferente, seja do ponto de vista teórico ou mesmo pragmático. Ao optar pelo caminho estrito, delimitado de uma ciência como a geografia, o desafio é pensar a região como consequiência de múltiplas dimensões da realidade. Não há, rigorosamente, dimensões puras da realidade, muitos menos sujeitos puros, já que todos fazemos parte de uma realidade híbrida. Latour já advertia:

Nos mesmos somos híbridos, instalados precariamente no interior das instituições cientificas, meio engenheiros, meio filósofos, um terço instruído sem que o desejássemos: optando por descrever as tramas por onde quer que estas nos levem. (LATOUR, 1994:91)

Pensar a cultura de um lado, a natureza de outro e a economia no meio e a política mais no canto, operando uma separação tipológica, nos parece pouco aprovado, já que nós mesmos somos "ontologicamente" híbridos. A cultura guarda, nos dias de hoje, uma economia e a economia sempre teve seu tanto de cultura, assim como a economia-cultura tem muito de política, pois o protecionismo agrícola Europeu, só para lembrar, resguarda-se na política, na economia e na cultura, como subterfúgio dıscursivo da tradição culinária.

A ambição de compreender essas múltiplas dimensões, que pode ser confundida como o retorno à síntese regional, pode parecer, num primeiro momento, questionável. Mas não se trata disso. Nem de uma síntese do espaço regional, com o objetivo de buscar a coesão expressa na paisagem entre os domínios físicos e humanos. Muito menos encontrar uma fórmula que permita entender o espaço em todas as dimensões (política, econômica, cultural, discursiva etc) e escalas formais (local, nacional, global) possíveis. No entanto, o esforço por romper as naturalizações coincide com a 
necessidade de entender os múltiplos processos que levaram à constituição do mundo atual, o que significa compreender as transformações espaciais advindas do processo de globalização e as cada vez mais "espacialidades diferenciais" (LACOSTE, 1994). Canclini (1999), analisando o embate e as interrelações entre o tradicional e o moderno na América Latina, nos chama a atenção para a hibridez cultural presentes nos espaços citadinos, deixando entender a ineficácia da afirmação do regional como algo estéril, estanque, puro. Segundo Canclini:

A sociabilidade híbrida que as cidades contemporâneas induzem nos leva a participar de forma intermitente de grupos cultos e populares, tradicionais e modernos. A afirmação do regional ou do nacional não tem sentido nem eficácia como condenação geral do exógeno - deve ser concebida agora como a capacidade de interagir com as múltiplas ofertas simbólicas internacionais a partir de posições próprias. (CANCLINI, 1999:354)

A "condenação do exógeno", característica fomentada pelas geografias que viram, ao longo das décadas, as regiões como entidades puras, coerentes, dotadas de "personalidades" e "individualidades", escondiam a hibridez implícita no conceito de região. Essa hidridez, "ontológica" em Latour (2000) e "modernizadora" para Canclini (1999), ou até mesmo as "impurezas" de Morin (1999) foram escamoteadas, purificadas pelos investimentos acadêmicos e da burocracia estatal, por meio do planejamento regional. O caminho para a naturalização foi composto por um discurso da pureza regional e da classificação, do culto ao singular que não permitia, sequer, as interações mais banais. Não é à toa que nos dias de hoje a possibilidade de interação, devido às redes e sistemas técnicos e mesmo a cultura, é utilizada por alguns como recurso para condenar a existência da região e consecutiva condenação da geografia regional.

Qual seria o caminho, então, para construção de uma geografia regional que busque articulação entre as escalas globais e locais, já que a escala global, a partir da sociedade em rede, é utilizada como justificativa para decretar o seu fim? Como articular as dimensões espaciais (política, econômica, cultural etc)? Em que medida esse seria um caminho para discutir as naturalizações da região?

Três ordens de interrogação são necessárias: escala, dimensão de existência espacial e nível de autonomia. Três elementos que precisam ser reavaliados em sua coexistência. A coexistência nos parece uma das boas saídas para responder essas interrogações. A coexistência de escalas nos leva a indagar sobre o grau diverso de articulação entre os espaços, seja no interior do Estado-Nação ou mesmo em áreas de fronteiras. A escala envolve a consideração do grau de influência de fenômenos exteriores na configuração regional. Apesar da influência da escala global (que não é puramente global) não é possível afirmar a inexistência de espaços cujas lógicas seguem questões locais. Isso acontece porque há, em nossas análises, uma lógica de subordinação da escala local à escala global, esta última como produto da economia: Esquecemos, no entanto, que escala global tem uma dimensão local que se globaliza, 
na medida que o puramente global não existe, pois estamos distantes da homogeneidade total, como podemos observar com a leitura de Robertson (2000) sobre a "glocalização" e ou mesmo Beck (1999), sobre as "translocalidades".

À coexistência de escalas devemos acrescentar a coexistência das dimensões espaciais (econômicas, culturais e políticas) do espaço na compreensão da região. A cultura carrega e comunica um forte peso econômico e político. As regiões francesas dos queijos e vinhos não são apenas realidades culturais, mas também econômicas e políticas, na medida que se transformam em plataformas de embates e disputas de poder numa base territorial definida. Comprar um vinho do Porto no CarrefourGoiânia, o próprio léxico já denuncia, é estabelecer relações simbólicas e econômicas com França e Portugal, tornando-se até mesmo símbolo de status social, uma vez o "acesso" a essas regiões tem um custo relativamente alto. Raciocínio semelhante emprega-se à exportação de telenovelas, a partir da divulgação de determinadas regiões brasileiras, como o Nordeste com seu tom pitoresco. Numa metáfora regional podemos dizer que as regiões estão sendo transportadas, comunicadas, pelas redes.

Outra questão refere-se à coexistência da autonomia regional. Esse debate não é novo e sua construção assentou-se na crítica da geografia regional vidalina. ${ }^{6} \mathrm{O}$ pressuposto básico seria aquele de que a região, como objeto concreto, poderia ser explicada por ela mesma e o trabalho do geógrafo seria o de decifrar a sua "personalidade". Esse discurso tem sido reproduzido de modo contínuo, da mesma forma que seu contrário, ou seja, de que a região não se explica por ela mesma. A explicação sempre estaria no exterior. A região é exterior em dois sentidos: 1 - porque os processos "globais" que determinam a configuração regional são exteriores; 2 - porque quem diz que aquilo é ou não uma região muitas vezes é exterior à região. Não seria interessante acusar níveis de coexistência de autonomia, ou, em todos os sentidos, a região seria definida pelo exterior? Não haveria mais uma região concreta, esperando por ser descrita? O Cariri cearense é reconhecido, aceito e cantado por aqueles que vivem na região, assim como em tantos outros lugares do Brasil. O debate sobre a governabilidade das regiões não seria um indicativo de que haveria níveis de autonomia escalar, inclusive com representatividade política? O que são os regionalismos, senão a expressão, o desejo, de um nível de autonomia? Supor que a região seja construída unicamente a partir de imperativos externos não significaria desprivilegiar outras construções regionais, elaboradas por agentes com menor grau de autonomia?

\footnotetext{
"Vale a pena citar as regiōes "virtuais" de Boisier (1996). Essas regiōes, sem contigüidade espacial, representariam os acordos de cooperação entre as regiões "pivotais" ou "associativas", em busca de acordos que possam beneficiar ambas.

Segundo La Blache (1954:40-41): "Hoje, todas as partes da terra estão em comunicação; o isolamento é uma anomalia que lembra um desafio, e não mais apenas entre regiões contíguas e vizinhas, mas também entre as longínquas, se estabeleceu contacto". A passagem citada coloca em dúvida a perspectiva de uma "única" interpretação regional em Vidal de La Blache. Ao contrário, como confirmou Gomes (1996) sua obra é resultado de "um cruzamento de influências" e interesses que desembocaram em propostas de regionalização do território francês ligadas às divisōes departamentais.
} 
A consideração das coexistências envolve a "hidridez do espaço" (SANTOS, 1997), o que não basta para que possamos pensar o conceito de região na e para a geografia. É imprescindível associá-lo a uma base territorial. Segundo Haesbaert:

\begin{abstract}
Região, portanto, não é um recorte geográfico qualquer, não é um território em sentido amplo (mas sim um determinado tipo de território) e também não é uma escala intranacional qualquer, pois para que a região exista é necessário que o território que a constitui seja a base concreta, produto e condicionante de uma desigualdade econômica (com um papel distinto na divisão inter-regional do trabalho) e uma especificidade político-cultural fundamentada em fenômenos concretos, muito variáveis em intensidade, mas em geral estreitamente associados: o regionalismo político e a identidade regional. (HAESBAERT, 1997:52)
\end{abstract}

Necessariamente essa base não precisa ser contínua. Rigorosamente, a contigüidade envolve uma certa "ilusão cartográfica": contigüidade e homogeneidade andaram juntas no espaço plano. As redes favorecem as "descontinuidades", as interações, entre escalas, nos permitindo falar em regiões que seguem uma lógica reticular. No entanto, como coloca Haesbaert (2000), é preciso considerar esses processos não como oposição entre uma "lógica zonal" e outra "lógica reticular", mas nas suas interações e correspondências, no seu "caráter relacional".

Para Haesbaert:

"Muitas vezes essa visão contínua existe apenas ao nível das representações ou da `ideologia regional', que tenta vender a imagem de uma região homogênea e efetivamente coesa".

(HAESBAERT, 2000:12)

Finalizando, há muito de regional nesse mundo. Os três elementos da receita que temperam o argumento do fim da região, quer sejam, a visão unilateral e homogênea da globalização, o fim do Estado-Nação como escala de referência e a emergência de uma sociedade estruturada em redes, não bastam para decretar o fim da região. É possível, isso sim, pensar numa outra região, afinal temos outras construções regionais. Mesmo nas perspectivas mais liberais constata-se a influência de uma literatura com forte peso do fator regional como as "economias regionais" e os "Estados-regiões" de Ohmae (1996). De outra ponta, na geografia econômica, também constatamos a forte presença da leitura regional. Benko:

Penso que a economia regional emergente pode ser considerada como um mosaico de regiões produtivas especializadas, com processos complexos de crescimento localizado, cada vez mais dependente, apesar de tudo, das outras regiões. (BENKO, 2000:68)

As mudanças no padrão de produção fordista, tanto nos países desenvolvidos quanto subdesenvolvidos, têm alterado paisagem de antigas regiões industriais. Para além das regiões rígidas, fruto do padrão locacional do fordismo, surgem regiões 
flexíveis, "ganhadoras", para utilizar a expressão de Benko \& Lipietz (1994). As regiões mudam à mercê dos imperativos do próprio movimento da sociedade. Mas, apesar de tudo, parece prevalecer um aspecto: a regere como noção eminentemente política, o que não excluí, de forma alguma, as "regiões ganhadoras", as regiões de comunidades e grupos ao longo dos tempos, muito menos a dimensão discursiva dos regionalismos e pragmática do planejamento regional. Enfim, a região existe, e no mundo pretensamente homogêneo, a regere irrompe com debate político e territorial.

\section{Conclusão ou aporias regionais?}

Por fim, o discurso do fim da região demonstra a nossa incapacidade de pensar a região a partir de outros princípios. Os argumentos oscilam entre a evidência, pouco sustentável pela analise empírica, de um mundo homogêneo, do fim das identidades em função da globalização, da falência do Estado Nação como entidade reguladora do território; para a emergência de um mundo cuja ordem territorial obedece a uma prerrogativa reticular. As "redes" (CASTELLS, 1999), também naturalizadas, decretaram o fim da região, como se tratasse de uma batalha entre redes com sua lógica fluída de um lado e a região com sua lógica fixa de outro. Contra esse discurso devemos impor o discurso do fim da naturalização e da pureza regional, indagando se a região, como categoria de análise, deveria permanecer presa numa definição unilateral. E mais ainda, se as redes e a emergência dos localismos e regionalimos não seriam indicativos suficientes de que, como noção eminentemente política, a região ainda vive. "Enfim, cada um o que quer aprova, o senhor sabe: pão ou pães, é uma questão de opiniães". Como no sertão de Guimarães Rosa, a região esta por toda parte.

REGIÕES PURAS E IMPURAS: UMA BREVE REFLEXÃO SOBRE AS NATURALIZAÇÕES DA REGIÃO NA GEOGRAFIA

Resumo: o presente artigo procura discutir o conceito de região a partir de suas naturalizações na geografia.

Palavras-chave: região, geografia, regionalização.

PURE REGIONS AND IMPURE REGIONS: A SHORTE REFLECTION ABOUT THE NATURALIZATIONS OF THE REGION IN THE GEOGRAPHY

Abstract: the present article tries to discuss the region concept starting from your naturalizations in the geography.

Keywords: geography, region, regionalization.

\section{BIBLIOGRAFIA}

AGNEW, John. 2000. From the political economy of regional to regional political economy. Progress. In.: Human Geography, 24 (1):101-110. 